\title{
EDDY VISCOSITY PROFILES FOR WAVE BOUNDARY LAYERS: VALIDATION AND CALIBRATION BY A k-w MODEL
}

\author{
Rafik Absi ${ }^{1}$; Hitoshi Tanaka ${ }^{2}$; Loreline Kerlidou ${ }^{3}$ and Alicia André ${ }^{4}$
}

\begin{abstract}
Eddy viscosity in wave boundary layers is a key parameter in coastal engineering. Two analytical eddy viscosity profiles present a particular interest for practical applications: the parabolic-uniform profile (Myrhaug 1982, van Rijn 1993, Liu and Sato 2006) and the exponential-linear profile (Gelfenbaum and Smith 1986, Beach and Sternberg 1988, Hsu and Jan 1998, Absi 2010). The aim of our study is to assess and validate these two profiles by: (1) investigation of eddy viscosity in steady fully developed plane channel flow; (2) comparisons with numerical results of the two equation baseline (BSL) $k$ - $\omega$ model (Menter 1994, Suntoyo and Tanaka 2009). Our study shows that these two profiles are able to describe the eddy viscosity distribution in the wave bottom boundary layer but for different wave conditions given by the parameter $a_{m} / k_{s}$, where $a_{m}$ is the wave orbital amplitude and $k_{s}$ the equivalent roughness. The exponential-linear profile is adequate for $a_{m} / k_{s}<500$, while the parabolic-uniform profile is more appropriate for $a_{m} / k_{s} \geq 500$. We suggest empirical formulations for the different coefficients which appear in these two profiles based on numerical results of the BSL $k-\omega$ model.
\end{abstract}

Keywords: wave boundary layers; eddy viscosity profiles; two-equation $k-\omega$ model, validation, calibration

\section{INTRODUCTION}

The resolution of some coastal engineering problems such as coastal erosion, transport of sediments and pollutants needs the knowledge of the boundary layer flow in the vicinity of the sea bed. The turbulent boundary layer generated by a sinusoidal wave has been the subject of many researchers: Kajiura (1968), Brevik (1981), Myrhaug (1982), Sleath (1990), Fredsoe and Deigaard (1992), Nielsen (1992), You et al. (1992), van Rijn (1993), Tanaka and Thu (1994), Madsen and Salles (1998) and others.

The distribution of eddy viscosity within the oscillatory boundary layer generated by waves in shallow waters is a key parameter in coastal engineering. Adequate description of eddy viscosity distribution in boundary layers is needed for accurate predictions of velocity profiles. Eddy viscosity is also related to sediment diffusivity which is involved in the calculation of sediment concentration profiles and therefore for the prediction of sediment transport by waves. For practical applications in coastal engineering, the eddy viscosity is obtained by mathematical models often based on statistical modeling of turbulence as two-equation models $(k-\varepsilon, k-\omega, \ldots)$, or by simple analytical or empirical models. Different assumptions were made about the variation of eddy viscosity with height in the bottom boundary layer: Kajiura (1968), Lundgren (1972), Smith (1977), Grant and Madsen (1979), Brevik (1981), Myrhaug (1982). We will investigate particularly two analytical eddy viscosity profiles for wave boundary layers namely, the parabolic-uniform profile (Myrhaug 1982, van Rijn 1993, Liu and Sato 2006) and the exponential-linear profile (Gelfenbaum and Smith 1986, Beach and Sternberg 1988, Hsu and Jan 1998, Absi 2010).

In order to assess and validate these profiles, we will first investigate eddy viscosity profiles obtained: (1) for steady flows, as a test case we will consider the fully developed plane channel flow; (2) from a two-equation $k-\omega$ model for the case of oscillatory flows. The validation and calibration of analytical profiles need comparisons with the period-averaged eddy viscosity obtained from the BSL k$\omega$ model for different wave conditions through the parameter $a_{m} / k_{s}$. The aim of is this study is to provide engineers simple analytical tools for practical use.

\section{TIME-INVARIANT EDDY VISCOSITY PROFILES FOR BOTTOM BOUNDARY LAYERS}

Eddy viscosity in turbulent oscillatory boundary layers can be assumed to be a time-independent and real-valued parameter (You et al. 1992). Different time-invariant eddy viscosity profiles (figure 1) were proposed for oscillatory flows by Kajiura (1968), Brevik (1981), Myrhaug (1982) and for combined steady and oscillatory flows by Lundgren (1972), Smith (1977), Grant and Madsen (1979).

\footnotetext{
${ }^{1}$ EBI-IPSL, Université Paris Grand Ouest (UPGO), 32 Bd du Port, Cergy-Pontoise, 95094, France

2 Department of Civil Engineering, Tohoku University, 6-6-06 Aoba, Sendai 980-8579, Japan

3 EBI-IPSL, Université Paris Grand Ouest (UPGO), 32 Bd du Port, Cergy-Pontoise, 95094, France

${ }^{4}$ EBI-IPSL, Université Paris Grand Ouest (UPGO), 32 Bd du Port, Cergy-Pontoise, 95094, France
} 


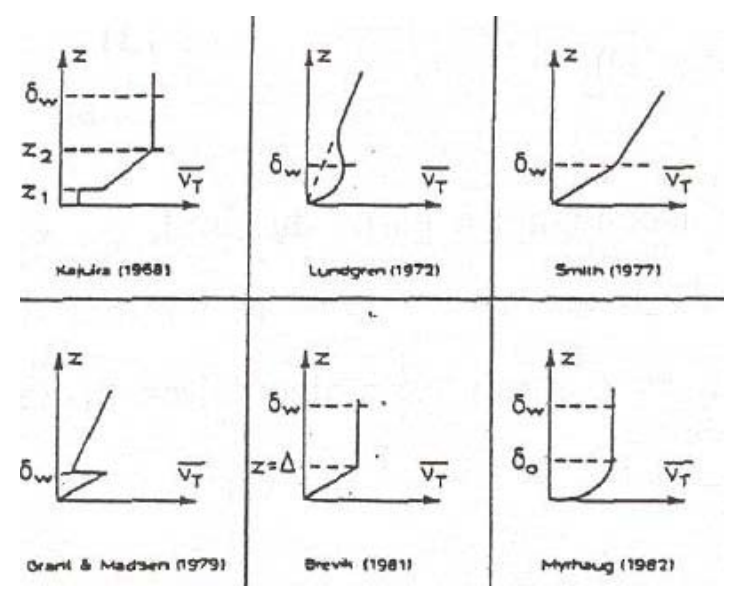

Figure 1. Assumptions for the variation of eddy viscosity with height in the bottom boundary layer (adapted from Fredsoe and Deigaard, 1992).

Among the eddy viscosity profiles for wave boundary layers, two seems to present a particular interest.

The first is given by a parabolic variation of eddy viscosity until the half of the boundary layer thickness then a uniform value (Myrhaug 1982, van Rijn 1993, Liu and Sato 2006, van Rijn 2007). We refer to this first profile as the parabolic-uniform profile. It is given by:

$$
v_{t}=\left\{\begin{array}{cc}
\kappa u_{*} Z\left(1-\frac{z}{\delta}\right) \quad \text { if } \quad \begin{array}{r}
z<\delta / 2 \\
v_{t \max }
\end{array} \text { if } \quad z>\delta / 2
\end{array}\right.
$$

where $\kappa$ is the von Karman constant ( $=0.41), u_{*}$ the friction velocity, $z$ the distance from the bottom and $\delta$ the boundary layer thickness.

The second is given by an exponential law modulated by a linear function (Gelfenbaum and Smith 1986, Beach and Sternberg 1988, Hsu and Jan 1998, Absi 2010). We refer to this second profile as the exponential-linear profile. It is given by:

$$
v_{t}=\alpha \kappa u_{*} \operatorname{zexp}\left(-C_{A} \frac{z}{\delta}\right)
$$

where $\alpha$ and $C_{A}$ are two coefficients.

We write equations (1) and (2) in dimensionless form respectively as:

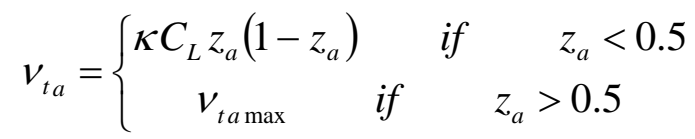

and

$$
v_{t_{a}}=\alpha \kappa z_{a} \exp \left(-C_{A} z_{a}\right)
$$

with $v_{t_{a}}=v_{t} /\left(u_{*} \delta\right) ; z_{a}=z / \delta$ and $v_{t_{a \max }}=\left(\kappa C_{L}\right) / 4$. In equation (3), we introduced an adjustment coefficient $C_{L}$. The initial profile, given by equation (1), didn't contain this coefficient $\left(C_{L}=1\right)$.

In order to assess and validate these profiles, we will investigate eddy viscosity profiles obtained from:

(1) Steady flows, we will consider as a test case the fully developed plane channel flow (figure 2) which is considered to be the simplest and most idealized boundary layer flow

(2) A two-equation $k-\omega$ model applied to oscillatory flows 


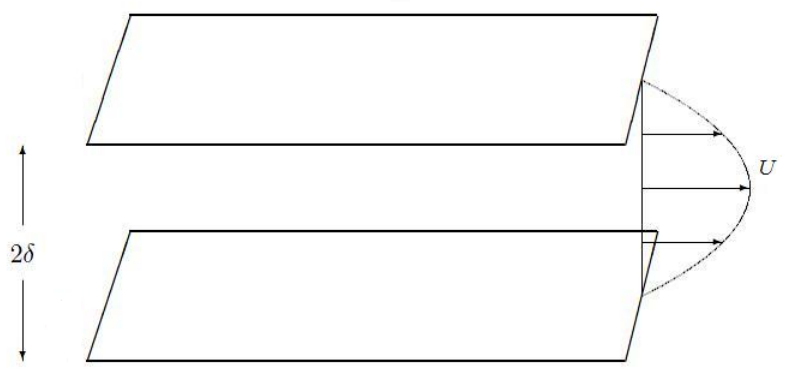

Figure 2. Test case: steady fully developed plane channel flow with smooth walls

\section{ANALYSIS OF EDDY VISCOSITY IN BOUNDARY LAYERS}

\section{Analytical eddy viscosity for steady flows}

In the equilibrium region of open-channel flows $\left(z^{+}>50\right)$, the turbulent kinetic energy (TKE) is given by $k \approx u_{*} \exp \left(-C_{k} z / \delta\right)$ (Nezu and Nakagawa 1993). Since in the inner region the streamwise velocity profile is given by the log-law, it is possible to write a mixing length as $l_{m}=\kappa z \exp \left(-C_{k} z / \delta\right)$ and therefore Eq. (2) for eddy viscosity (Absi 2012).
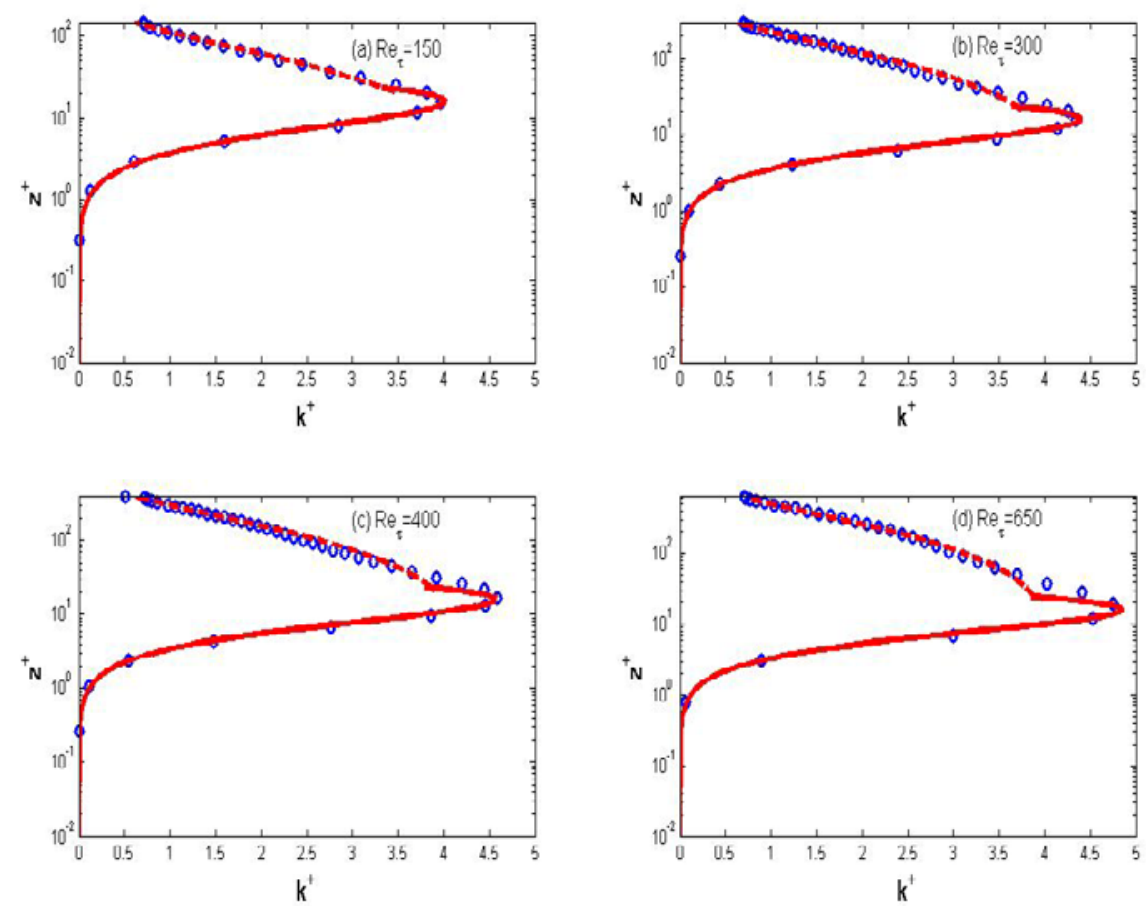

Figure 3. Analytical profiles for turbulent kinetic energy (TKE) for turbulent channel flow with smooth walls; dashed lines: TKE profile of Nezu and Nakagawa (1993); solid lines: TKE profile of Absi (2008); symbols: DNS data. (Absi et al. 2011, Absi 2012) 

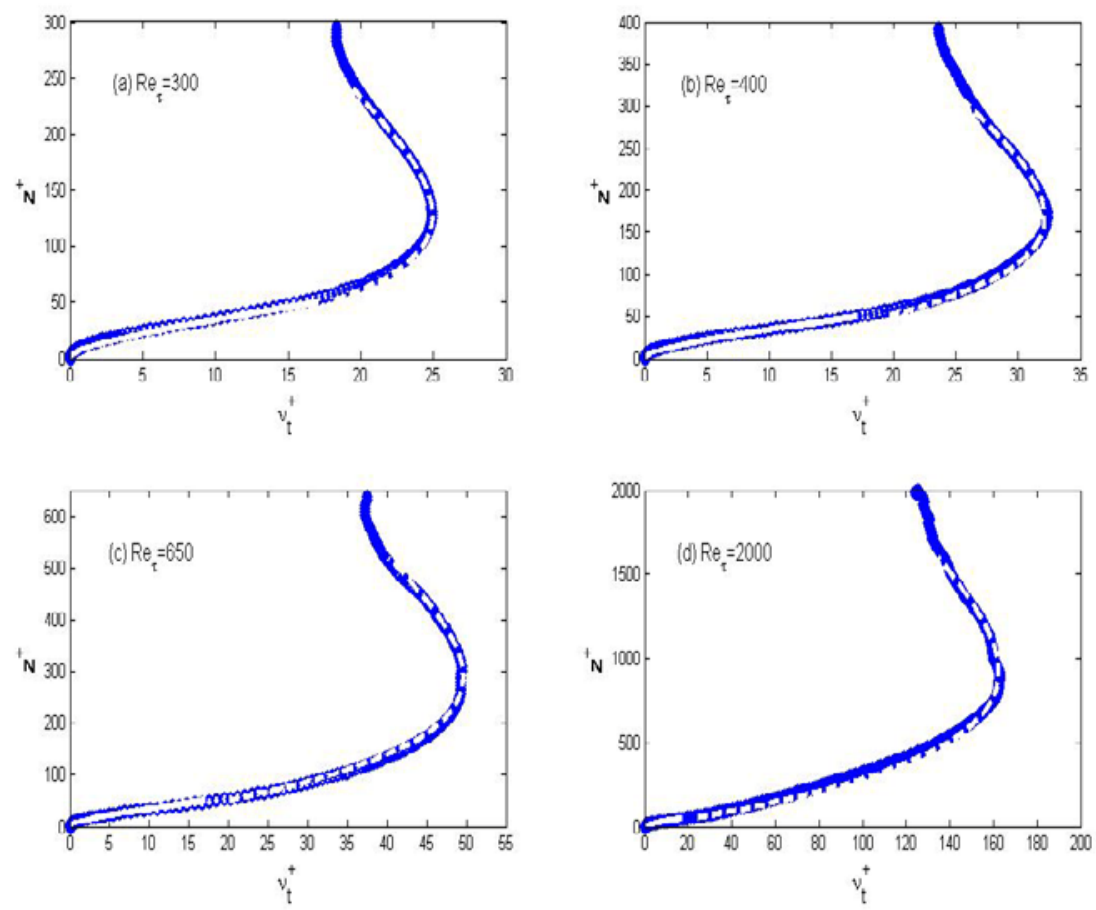

Figure 4. Analytical eddy viscosity profiles for turbulent channel flow with smooth walls; white dashed lines: Eq. (2); white solid lines: eddy viscosity based on van Driest mixing length equation; symbols (=blue bold solid line): DNS data. (Absi et al. 2011, Absi 2012).

Figure 3 shows TKE profiles given by Nezu and Nakagawa (1993) and Absi (2008), while figure (4) presents eddy viscosity profiles. In these figures, variables with the superscript of + are those nondimensionalized by the friction velocity and the kinematic viscosity as $z^{+}=z u_{*} / v ; k^{+}=k / u_{*} ; v_{t}^{+}=v_{t} / v$. Comparisons with Direct Numerical Simulation (DNS) data (of Iwamoto et al. 2002 and Hoyas and Jiménez 2006) show that, for steady plane channel flow with smooth walls, Eq. (2) allows accurate description (white dashed lines, figure 4) of DNS in the equilibrium region (Absi et al. 2011, Absi 2012). For $Z^{+}<50$, the eddy viscosity profile is based on van Driest mixing length equation (white solid lines, figure 4). Figure (4) shows that, for high friction Reynolds numbers, this layer $\left(\mathrm{z}^{+}<50\right)$ tends to be very small compared to the main profile given by Eq. 2 (figure 4.d). This could explain why in wave bottom boundary layers with large Reynolds numbers this layer is not observed and the profile is described mainly by Eq. (2). Eddy viscosity profiles of figure (4) are for a flat smooth wall, bottom roughness increases this effect and seems explain clearly why eddy viscosity is described only by Eq.(2) in wave boundary layers.

\section{Eddy viscosity distribution obtained by a two-equation k-w model}

Eq. (2) for eddy viscosity is validated for the case of steady plane channel flow. However for use in wave boundary layers, we need to assess this equation for the case of oscillatory flows. Eq. (2) is therefore analyzed by the baseline (BSL) k- $\omega$ model proposed by Menter (1994). This model allows accurate prediction of velocity profiles in oscillatory boundary layers (Suntoyo and Tanaka 2009). The BSL $\mathrm{k}-\omega$ model is a two-equation model that gives results similar to the $\mathrm{k}-\omega$ model of Wilcox (1988) in the inner boundary layer but changes gradually to the $k-\varepsilon$ model of Jones and Launder (1972) towards the outer boundary layer and the free stream velocity. The blending between the two regions is done by a blending function F1 changing gradually from one to zero in the desired region. Equations of turbulent kinetic energy $k$, specific dissipation $\omega$ and eddy viscosity are given respectively by:

$$
\frac{\partial k}{\partial t}=\frac{\partial}{\partial z}\left\{\left(v+v_{t} \sigma_{k \omega}\right) \frac{\partial k}{\partial z}\right\}+v_{t}\left(\frac{\partial u}{\partial z}\right)^{2}-\beta^{*} \omega k
$$




$$
\begin{gathered}
\frac{\partial \omega}{\partial t}=\frac{\partial}{\partial z}\left\{\left(v+v_{t} \sigma_{\omega}\right) \frac{\partial \omega}{\partial z}\right\}+\gamma\left(\frac{\partial u}{\partial z}\right)^{2}-\beta \omega^{2}+2\left(1-F_{1}\right) \sigma_{\omega 2} \frac{1}{\omega} \frac{\partial k}{\partial z} \frac{\partial \omega}{\partial z} \\
v_{t}=\frac{k}{\omega}
\end{gathered}
$$

The constants of the model are given by $\sigma_{k \omega}=0.5, \beta^{*}=0.09, \sigma_{\omega}=0.5, \gamma=0.553$ et $\beta=0.075$ (Suntoyo and Tanaka 2009).

In order to allow a validation of analytical eddy viscosity profiles $v_{t a}\left(z_{a}\right)$ by the two-equation BSL k- $\omega$ model, we will apply the following method (figure 7):

(1) Obtain time-dependent eddy viscosity $v_{t a}\left(z_{a}, t\right)$ from BSL k- $\omega$ model

(2) Calculate the eddy viscosity averaged over one period (time-independent) $\overline{v_{t a}}\left(z_{a}\right)$

(3) Compare the period-averaged eddy viscosity obtained from the BSL k- $\omega$ model $\overline{v_{t a}}\left(z_{a}\right)$ with the analytical profiles $v_{t a}\left(z_{a}\right)$

\section{Turbulence model}

Two-equation model

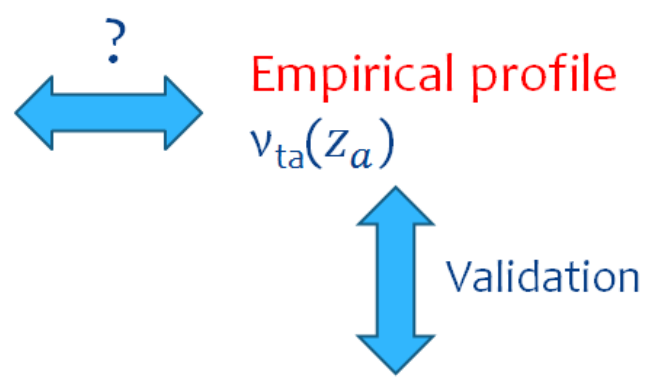

Eddy viscosity $v_{\mathrm{ta}}\left(z_{a}, t\right)$

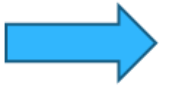

average over one period of $v_{\mathrm{ta}}\left(z_{a}, t\right) \rightarrow v_{\mathrm{ta}}\left(z_{a}\right)$

Figure 5. Summary of the approach used for the present study.

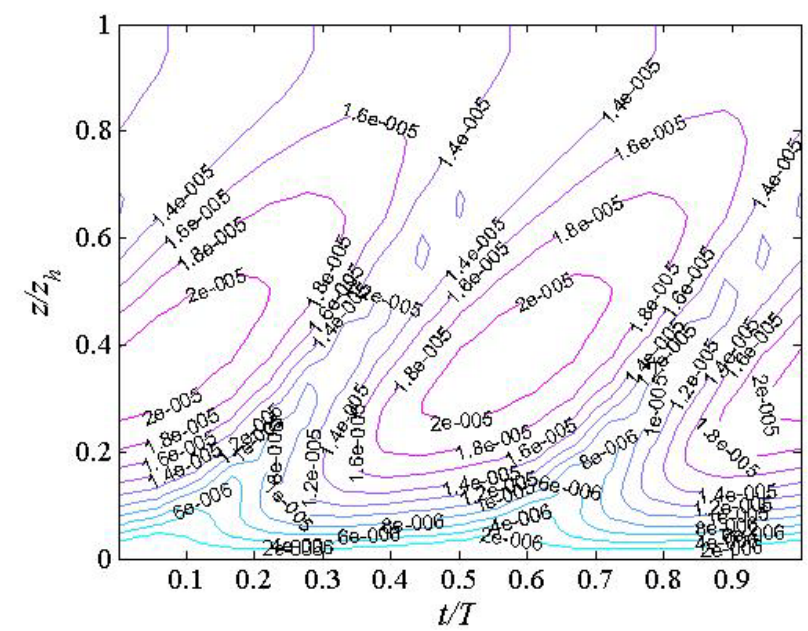

Figure 6. Temporal and Spatial Variation of dimensionless eddy viscosity for a sinusoidal wave obtained by the BSL $k-w$ model, Flow conditions : $U_{0}=3,63 \mathrm{~m} / \mathrm{s} ; a_{m}=1,73 \mathrm{~m} ; \mathrm{T}=3 \mathrm{~s} ; \mathrm{k}_{\mathrm{s}}=1,5 \mathrm{~cm}, \mathrm{Re}=437000$.

Figure (6) presents temporal and spatial variation of dimensionless eddy viscosity for a sinusoidal wave given by $U(t)=U_{0} \sin (\omega t)$. Figure (7) shows comparison between period-averaged eddy viscosity obtained from the BSL k- $\omega$ model (symbols) and analytical profile of Eq. (2) (dashed line). Even if the eddy viscosity is highly time-dependent (figure 6), the period-averaged dimensionless eddy 
viscosity (Figure 7) has a shape which is well described by the exponential-linear analytical profile given by Eq. (2) for $\mathrm{z} / \mathrm{z}_{\mathrm{h}}<0.6$ (figure 7) where $\mathrm{z}_{\mathrm{h}}$ is the water depth or the distance from the wall to the axis of symmetry (for oscillatory water tunnel experiments) or free surface.

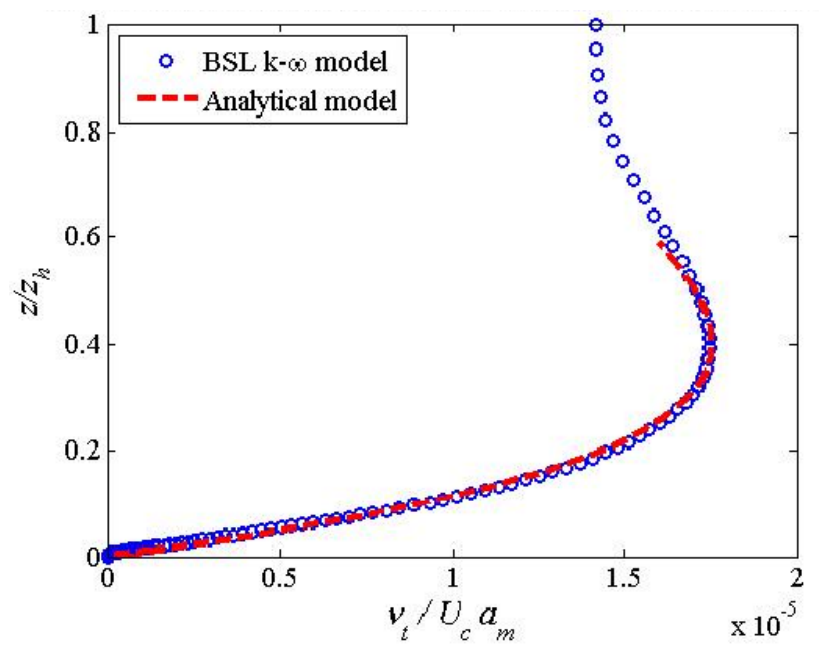

Figure 7. Period-averaged dimensionless eddy viscosity for a sinusoidal wave.

At the present stage, the exponential-linear profile (Eq. 2) is validated by both eddy viscosity profiles for steady plane channel flow (figure 4) and with period-averaged eddy viscosity obtained by the BSL k- $\omega$ model for sinusoidal wave for $a_{m} / k_{s}=115$ (figure 7). However, it is important to provide a validation through comparisons for different wave conditions.

\section{VALIDATION FOR SINUSIDAL WAVES FOR DIFFERENT FLOW CONDITIONS}

Figure (8) shows that the parabolic-uniform profile (Eq. 1) allows a good description of eddy viscosity for $a_{m} / k_{s} \geq 500$.

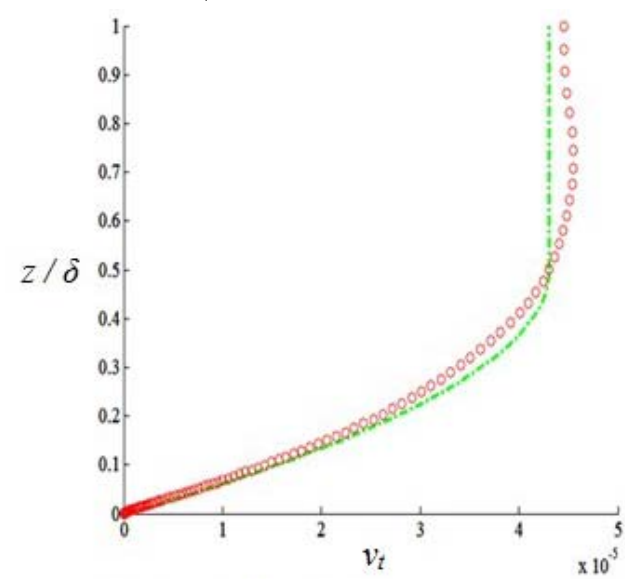

(a) $a_{m} / k_{s}=500$

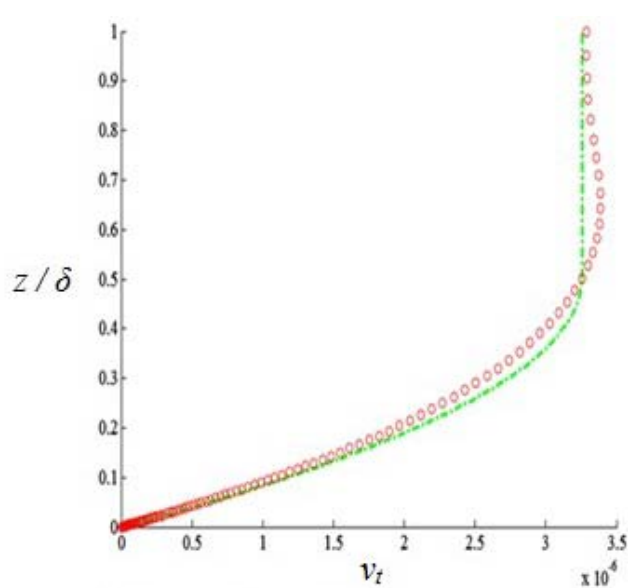

(b) $a_{m} / k_{s}=5000$

Figure 8. Validation of analytical eddy viscosity profile for $a_{m} / k_{s} \geq 500$. Symbols: period-averaged eddy viscosity obtained from the BSL $k-\omega$ model for a sinusoidal wave; curves: parabolic-uniform eddy viscosity profile (Eq. 1).

However, figure (9) shows that the exponential-linear profile (Eq. 2) allows accurate description of eddy viscosity for $a_{m} / k_{s}<500$ and a distance from the bottom $z / \delta<0.8$. 


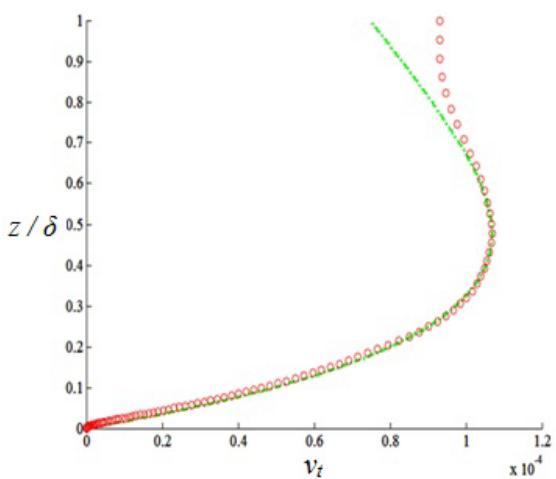

(a) $a_{m} / k_{s}=150$

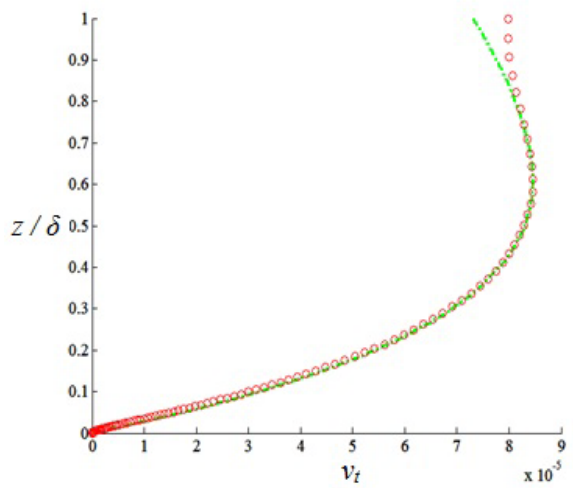

(d) $a_{m} / k_{s}=250$

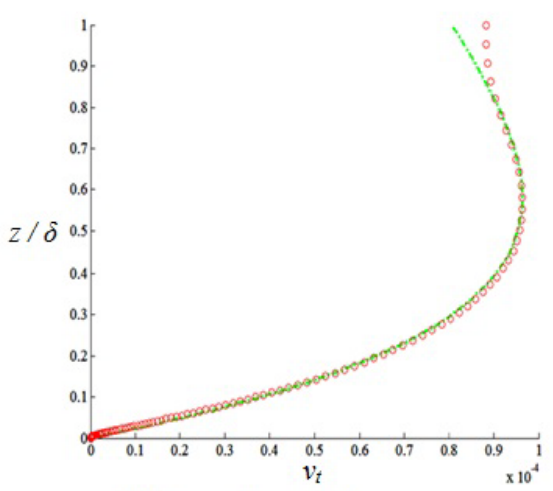

(b) $a_{m} / k_{s}=200$

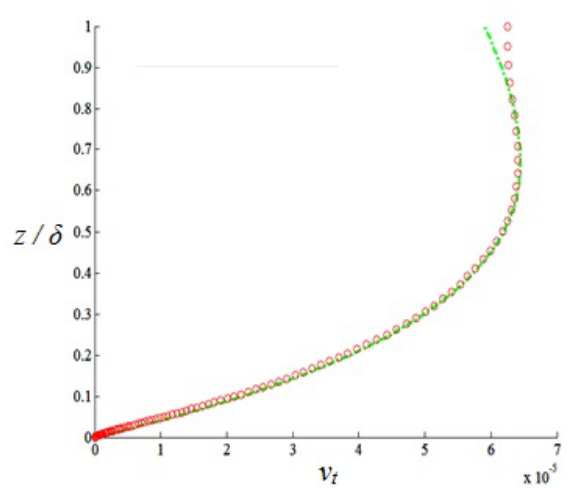

(d) $a_{m} / k_{s}=350$

Figure 9. Validation of analytical eddy viscosity profile for $a_{m} / k_{s}<500$. Symbols: period-averaged eddy viscosity obtained from the BSL $k-\omega$ model for a sinusoidal wave; curves: exponential-linear eddy viscosity profile (Eq. 2).

\section{CALIBRATION OF THE TWO ANALYTICAL EDDY VISCOSITY PROFILES}

Our study shows that the coefficients of the two analytical eddy viscosity profiles (parabolicuniform and exponential-linear) are not constants and should depend on wave conditions through the parameter $a_{m} / k_{s}$.

From the analysis presented in figure (10), we propose the following equations for the different coefficients:

$$
\begin{gathered}
C_{L}=0.4\left(a_{m} / k_{s}\right)^{-1.1} \\
\alpha=0.2\left(a_{m} / k_{s}\right)^{-0.97} \\
C_{A}=29.7\left(a_{m} / k_{s}\right)^{-0.52}
\end{gathered}
$$




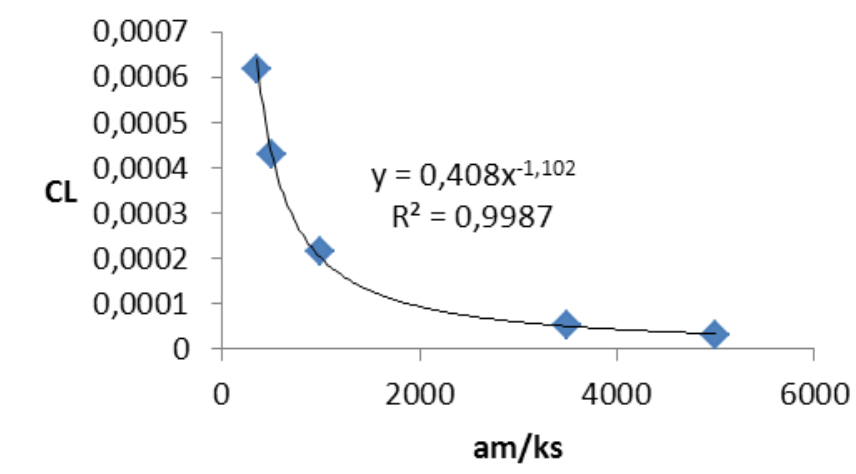

(a)

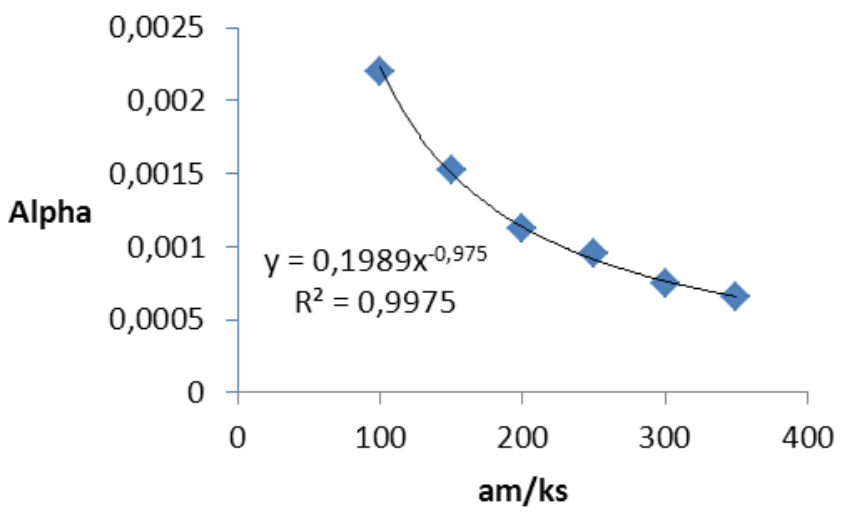

(b)

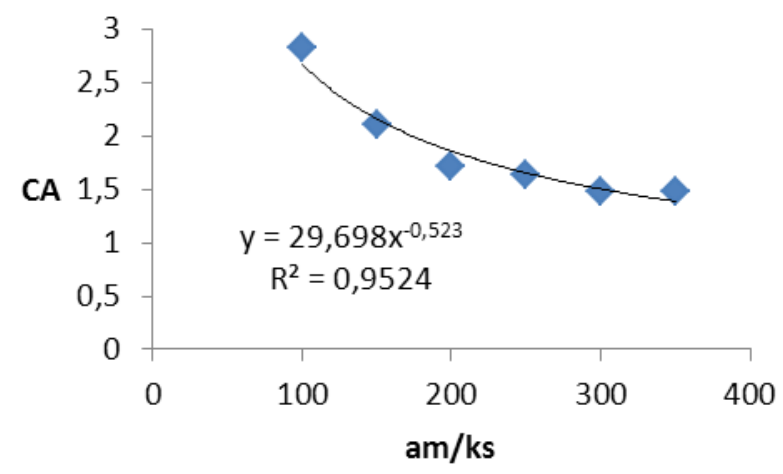

(c)

Figure 10. Calibration of the two eddy-viscosity profiles

\section{THE CASE OF AN ASYMMETRIC WAVE}

Figure (11.a) presents temporal and spatial variation of dimensionless eddy viscosity for asymmetric waves given by $U(t)=U_{1} \sin (\omega t)-U_{2} \cos (2 \omega t)$. Figure (11.b) shows comparison between period-averaged eddy viscosity obtained from BSL k- $\omega$ model (symbols) and analytical profile of Eq. (2) (dashed line). Even for the case of asymmetric wave, the period-averaged dimensionless eddy viscosity has a shape which is well described by Eq. (2) for $\mathrm{z} / \mathrm{z}_{\mathrm{h}}<0.5$ (figure 11.b). Figures (7) and (11.b) shows that the period-averaged eddy viscosity profile for sinusoidal wave is different from the profile of asymmetric wave. This indicates that the period-averaged eddy viscosity profile should depend on the wave non-linearity parameter given by $N_{i}=\left(U_{1}+U_{2}\right) /\left(2 U_{1}\right)$ or $N_{i}=U_{c} / \hat{u}$, where $U_{c}$ is the velocity at wave crest and û is the total velocity amplitude. We need therefore, for asymmetric waves, a specific calibration for parameters of Eq. (2). 


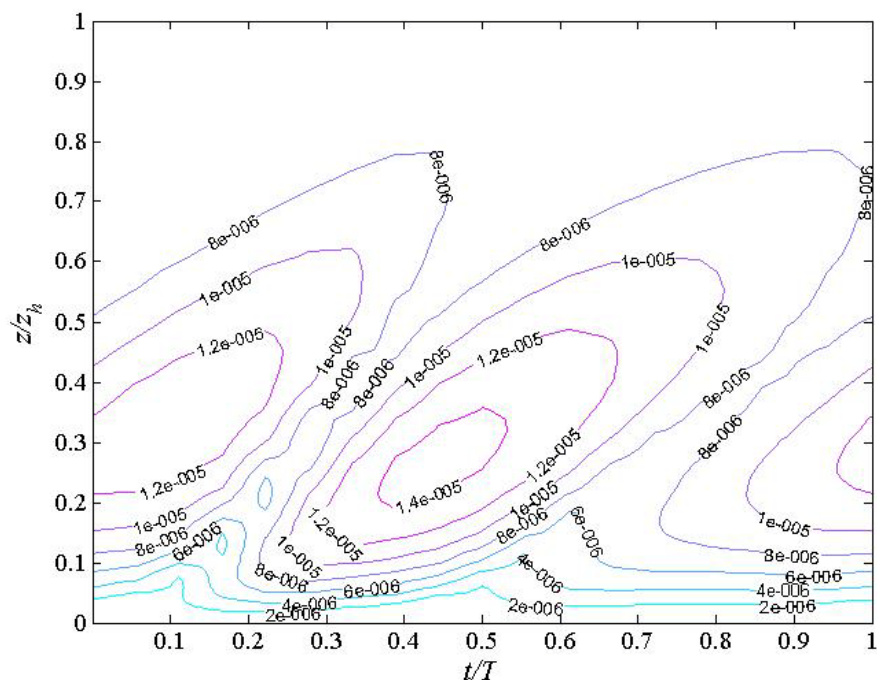

(a)

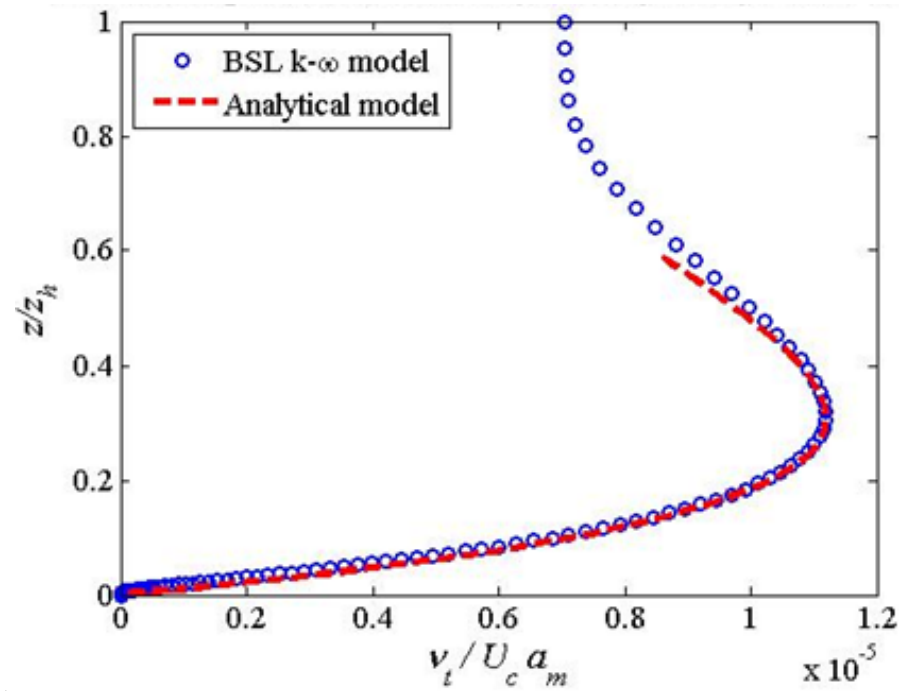

Figure 11. Dimensionless eddy viscosity for asymmetric wave $\mathrm{N}_{\mathrm{i}}=0.67$; (a) Temporal and Spatial Variation obtained by BSL $k-\omega$ model; (b) Period-averaged dimensionless eddy viscosity

\section{CONCLUSIONS}

The aim of is this study was to provide simple analytical tools for practical use in coastal engineering. We validated and calibrated two analytical eddy viscosity profiles by numerical results of a two-equation k- $\omega$ model for the case of sinusoidal wave for different wave conditions (figure 12). Our study shows that:

- For practical applications the period-averaged eddy viscosity could be described by simple analytical formulations

- The parabolic-uniform profile allows a good description of eddy viscosity for $a_{m} / k_{s} \geq 500$.

- The exponential-linear profile allows accurate description of eddy viscosity for $a_{m} / k_{s}<500$ for a distance from the bottom $\mathrm{z} / \delta<0.8$.

- The parabolic-uniform profile needs an adjustment parameter $C_{L}$

- Coefficients in the two analytical eddy viscosity profiles (parabolic-uniform and exponentiallinear) are not constants and depend on parameter $a_{m} / k_{s}$, we proposed equations for these coefficients 
- For asymmetric waves, eddy viscosity profile depends on the wave non-linearity parameter and requires therefore a specific calibration.
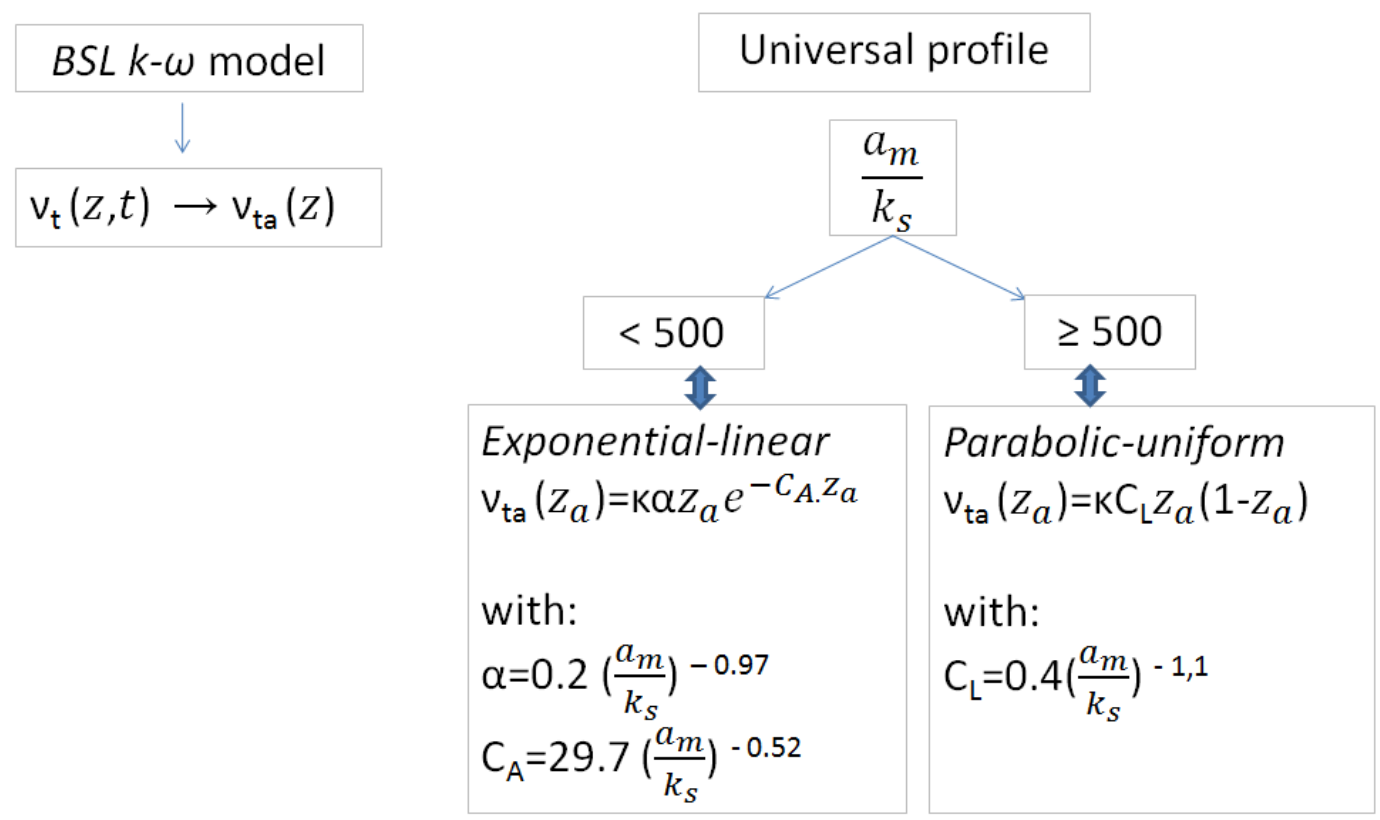

Figure 12. Summary of the present study

\section{ACKNOWLEDGMENTS}

The first author is grateful for the financial support provided by Japan Society for the Promotion of Science (JSPS), within the FY2010 JSPS Invitation Fellowship Program for Research in Japan (No. S10168).

\section{REFERENCES}

Absi, R. 2008. Analytical solutions for the modeled k equation, Journal of Applied Mechanics, ASME, 75(4), 044501.

Absi, R. 2010. Concentration profiles for fine and coarse sediments suspended by waves over ripples: An analytical study with the 1-DV gradient diffusion model, Advances in Water Resources, 33, 411-418.

Absi, R. 2012. Analytical modeling of turbulent flows in a plan channel with smooth walls, Submitted.

Absi, R., S. Marchandon, and M. Lavarde. 2011. Turbulent diffusion of suspended particles: analysis of the turbulent Schmidt number, Defect and Diffusion Forum, Trans Tech Publications, 312-315, 794-799.

Beach, R.A., and R.W. Sternberg. 1988. Suspended sediment transport in the surf zone: response to cross-shore infragravity motion. Marine Geology, 80, 61-79.

Brevik, I. 1981. Oscillatory rough turbulent boundary layers, Journal of Waterways, Port, Coastal and Ocean Engineering. ASCE, 103, 175-188.

Fredsoe, J., and R. Deigaard. 1992. Mechanics of coastal sediment transport, World Scientific Publishing, 369 pp.

Gelfenbaum, G., and J.D. Smith. 1986. Experimental evaluation of a generalized suspended-sediment transport theory. In Shelf Sands and Sandstones (Knight, R. J. and McLean, J. R., eds.), Canadian Society of Petroleum Geologists, Memoir, pp. 133-144.

Grant, W.D., and O.S. Madsen. 1979. Combined wave and current interaction with a rough bottom. Journal of Geophysical Research. 84(C4), 1797-1808.

Hoyas, S., and J. Jiménez. 2006. Scaling of velocity fluctuations in turbulent channels up to $\operatorname{Re}_{\tau}=2003$, Phys. Fluids, 18, 011702.

Hsu, T.-W., and C.-D. Jan. 1998. Calibration of Businger-Arya type of eddy viscosity models parameters. Journal of Waterway, Port, Coastal and Ocean Engineering, ASCE, Vol. 124(5), 281284. 
Iwamoto, K., Y. Suzuki, and N. Kasagi. 2002. Reynolds number effect on wall turbulence: toward effective feedback control, International Journal of Heat Fluid Flow, 23, 678.

Jones, W.P., and B.E. Launder. 1972. The prediction of laminarization with a two-equation model of turbulence. International Journal of Heat Mass Transfer, 15, 301-314.

Kajiura, K. 1968. A model of the bottom boundary layer in water waves. Bulletin of the Earthquake Research Institute. 46, 75-123.

Liu, H., and S. Sato. 2006. A two-phase flow model for asymmetric sheet-flow conditions. Coastal Engineering, 53, 825-843.

Lundgren, H. 1972. Turbulent currents in the presence of waves, Proceedings of $13^{\text {th }}$ International Conference on Coastal Engineering, ASCE, 623-634.

Madsen, O.S., and P. Salles. 1998. Eddy viscosity models for wave boundary layers, Proceedings of $26^{\text {th }}$ International Conference on Coastal Engineering, ASCE, 2615-2627.

Menter, F.R. 1994. Two-equation eddy-viscosity turbulence models for engineering applications. AIAA Journal, 32 (8), 1598-1605.

Myrhaug, D. 1982. On a theoretical model of rough turbulent wave boundary layers, Ocean Engineering. 9(6), 547-565.

Nezu, I., and H. Nakagawa, 1993. Turbulence in Open-Channel Flows, A. A. Balkema, ed.

Nielsen, P. 1992. Coastal bottom boundary layers and sediment transport, World Scientific, 324 p.

Sleath, J.F.A. 1990. Seabed boundary layers, The Sea, Vol. 9: Ocean Engineering Science, Bernard Le Méhauté, Daniel M. Hanes (Eds.), 693-728.

Smith, J.D. 1977. Modeling of sediment transport on continental shelves, In the Sea, 6, Intersience, N.Y., 538-577.

Suntoyo, and H. Tanaka. 2009. Effect of bed roughness on turbulent boundary layer and net sediment transport under asymmetric waves, Coastal Engineering, 56(9), 960-969.

Tanaka, H. and A. Thu. 1994. Full-range equation of friction coefficient and phase difference in a wave-current boundary layer, Coastal Engineering, 22, 237-254.

van Driest, E.R. 1956. On turbulent flow near a wall, J. Aero. Sci., 23, 1007-1011.

van Rijn, L.C. 1993. Principles of sediment transport in River, Estuaries and Coastal Seas. Aqua Publishing, Amsterdam.

van Rijn, L.C. 2007. Unified view of sediment transport by currents and waves II: Suspended transport, Journal of Hydraulic Engineering, ASCE, 133(6), 668-689.

Wilcox, D.C. 1988. Reassessment of the scale-determining equation for advanced turbulent models. AIAA Journal, 26 (11), 1299-1310.

You, Z.J., D.L. Wilkinson, and P. Nielsen. 1992. Velocity distribution in turbulent oscillatory boundary layer, Coastal Engineering, 18, 21-38. 